\title{
Flow Cytometry Crossmatch: A Sensitive Technique for Assessment of Acute Rejection in Renal Transplantation
}

\author{
A. Piazza, D. Adorno, E. Poggi, L. Borrelli, O. Buonomo, F. Pisani, M. Valeri, N. Torlone, C. Camplone, \\ P.I. Monaco, D. Fraboni, and C.U. Casciani
}

$\mathrm{T}$ HE PRESENCE of anti-donor-specific antibodies before transplantation, detected using a complementdependent lymphocytotoxic test (CDC), is an absolute contraindication to renal transplant; moreover, some authors have observed a high incidence of acute rejection (ARj) episodes ${ }^{1-5}$ and a decreased graft survival ${ }^{6-9}$ in kidney transplant recipients with a positive flow cytometric crossmatch (FCXM) before transplantation. FCXM is more advantageous than $\mathrm{CDC}$ in that it shows a higher sensitivity in the detection of preformed antibodies ${ }^{10}$ and allows the simultaneous detection of complement-activating and nonactivating alloantibodies, the class of donor specific antibodies (IgG and/or IgM), and the donor target cells ( $\mathrm{T}$ and/or B lymphocytes).

Nevertheless, pretransplant crossmatching can only give an idea of presensitization. It is not able to identify all patients who will experience rejection following transplantation. Although needle core biopsy represents the most effective tool for diagnosing rejection, many efforts have been made to monitor rejection using less invasive procedures. The aim of this study was to demonstrate that among the many approaches used to monitor rejection in renal transplant recipients FCXM routinely performed after transplantation represents a specific, sensitive, and noninvasive method for monitoring donor specific immune responses. For this purpose FCXM was performed in the first 3 months after transplant on 42 patients who had received cadaveric kidney transplant.

\section{MATERIALS AND METHODS Patients}

Of the kidney transplant (KT) recipients who received cadaveric kidney transplants in the Transplant Unit of Department of Surgery at Tor Vergata University of Rome between October 1995 and June 1997, only those who satisfied the following criteria were included in the study: pretransplant negative CDC and FCXM cross-match; clinical follow-up for at least 3 months after transplantation; available donor spleen lymphocytes. All selected KT recipients were monitored using FCXM during the first 3 months after transplantation. Patient sera were taken before (current sera) the transplant and after the transplant on days 7, 14, 30, 60, and 90 and when ARj was suspected. All sera were checked for autoantibodies using FCXM. Donor spleen lymphocytes were stored in liquid nitrogen until used. Organ allocation was based on the best

Table 1. Kidney Transplant Recipients Characteristics

\begin{tabular}{lc}
\hline Age, mean \pm SD & $44 \pm 9.88$ \\
Male/Female (\%) & $62 / 38$ \\
No of transfused patients (\%) & 9 \\
No of retransplant (\%) & 2 \\
HLA-AB mismatches: mean \pm SD & $2.45 \pm 0.87$ \\
HLA-DR mismatches: mean \pm SD & $0.61 \pm 0.53$ \\
Acute rejection episodes: mean \pm SD & $0.38 \pm 0.65$ \\
\hline
\end{tabular}

donor-recipient HLA matching; matching priority was HLA-DR, HLA-B and HLA-A. The patients' characteristics are presented in Table 1.

\section{Immunosuppressive Protocol}

Patients were treated with a standard triple-therapy immunosuppression protocol consisting of $8 \mathrm{mg} / \mathrm{kg}$ per day of cyclosporine, 1.5 $\mathrm{mg} / \mathrm{kg}$ per day of azathioprine, and $20 \mathrm{mg} /$ day of prednisone. All patients received $500 \mathrm{mg}$ of methylprednisolone on the day of transplantation. Rejection treatment consisted of three doses of methylprednisolone ( 0.5 to $1 \mathrm{~g} /$ dose) .

\section{Clinical Outcome Parameters}

All cases of renal dysfunction were investigated by assessing clinical symptoms and confirmed in general by needle core biopsy. No transplanted organ was lost during the period of our study for immunologic reasons. Sixteen ARj episodes occurred in 12 patients; all the first ARj episodes appeared within 15 days after transplantation, and four patients had a second rejection episode within the second month.

\section{FCXM}

A modification of the three-colour fluorescence technique described by Bray ${ }^{11}$ was used. In brief, donor spleen lymphocytes $\left(2.5 \times 10^{5}\right)$ and $75 \mu \mathrm{L}$ of serum were incubated at room temperature for $30 \mathrm{~min}$, then washed twice with phosphate buffered saline containing $5 \%$ fetal bovine serum and $0.1 \%$ sodium azide (PBSFlow). The lymphocytes were then incubated for $30 \mathrm{~min}$ at $4^{\circ} \mathrm{C}$ with $50 \mu \mathrm{L}$ of diluted fluorescein isothiocyanate-conjugated goat

From the C.N.R. Institute of Tissue Typing, Unit of Rome; and Department of Surgery, Tor Vergata University, Rome, Italy.

Address reprint requests to Dr D. Adorno, Osp S. Eugenio, Tissutale Sez Di Roma, CNR IST Tipizzazione, \% Clinica Chirurgica, Piazzale dell Umanesimo 10, 00144 Rome, Italy. 
Table 2. Analysis of HLA-ABDR Mismatches and Serum Creatinine Levels According to FCXM Status

\begin{tabular}{lcc}
\hline & $\begin{array}{c}\text { FCXM positive }^{*} \\
(\mathrm{n}=11 \text { patients })\end{array}$ & $\begin{array}{c}\text { FCXM negative* }^{*} \\
(\mathrm{n}=31 \text { patients })\end{array}$ \\
\hline HLA-AB mismatches & $3.0 \pm 0.6$ & $2.25 \pm 0.88$ \\
HLA-DR mismatches & $0.72 \pm 0.61$ & $0.58 \pm 0.49$ \\
Serum creatinine levels (mg/dL) & $3.4 \pm 2.2$ & $1.9 \pm 0.67$ \\
\hline
\end{tabular}

${ }^{*}$ Data are given as mean \pm standard deviation.

$\mathrm{F}\left(\mathrm{ab}^{\prime}\right)_{2}$ anti-human IgG or IgM (Dako-Denmark) to determine the class of bound alloantibodies; $5 \mu \mathrm{L}$ of peridinin chlorophyll protein-conjugate monoclonal antibodies anti-CD3 and $5 \mu \mathrm{L}$ of phycoerythrin-conjugated monoclonal antibodies anti-CD20 (Becton Dickinson, San Jose, Calif) were also added to the cell suspension to identify donor $\mathrm{T}$ and $\mathrm{B}$ lymphocytes. After incubation the cells were washed twice with PBS-Flow and resuspended in $200 \mu \mathrm{L}$ of $1 \%$ paraformaldehyde in PBS until analysis. For all FCXMs analyzed, donor lymphocytes were incubated with the test serum, a positive control serum (a pool of patients' sera with $>90 \%$ panel reactive antibodies) and a negative control serum (a pool of $>5$ sera from healthy male subjects). Samples were analyzed using a FACScan flow cytometer and FACScan software (Becton-Dickinson). Data were collected with logarithmic amplification, and fluorescence intensity was displayed on 1024 channels (4-decade $\log$ scale). A channel shift of more than 2 standard deviations (SD) between the mean log fluorescence of the negative control sample and test samples was considered to be a positive FCXM.

\section{Statistical Analysis}

The chi-square test and Mann-Whitney two-sample test were used for statistical comparison. $P<.05$ was considered significant.

\section{RESULTS}

Of the 42 KT recipients monitored using FCXM during the first 3 months after transplantation, $11(26 \%)$ had proved at least once IgG-FCXM positive. In all but 3 of the 11 patients, IgG positivity was directed at both $\mathrm{T}$ and $\mathrm{B}$ donor lymphocytes; the other three patients showed a positive FCXM directed exclusively at B donor lymphocytes. Moreover, 6 of the 11 patients who presented an IgG-positive FCXM were also IgM positive.

Analyzing HLA-ABDR mismatches in the FCXM-positive and FCXM-negative patients we found an increase, although it was not significant, in the degree of HLA-AB mismatching in the first group compared with the second (HLA-AB mismatch mean \pm SD: $3 \pm 0.06$ versus $2.25 \pm$ $0.88)$. On the other hand, no differences were observed in the degree of HLA-DR mismatching in the two groups (HLA-DR mismatch mean \pm SD: $0.72 \pm 0.61$ versus $0.58 \pm$ $0.49)$.

The serum creatinine level at 3 months after transplantation was also measured. Correlating these data with FCXM positivity we observed that the mean serum creatinine value in FCXM-positive patients was higher than that seen in FCXM-negative patients $(3.4 \pm 2.2$ versus $1.9 \pm$ $0.67 \mathrm{mg} / \mathrm{dL}$ : marginally significant with Mann-Whitney twosample test) (Table 2).

Correlating $\mathrm{ARj}$ and posttransplant FCXM monitoring

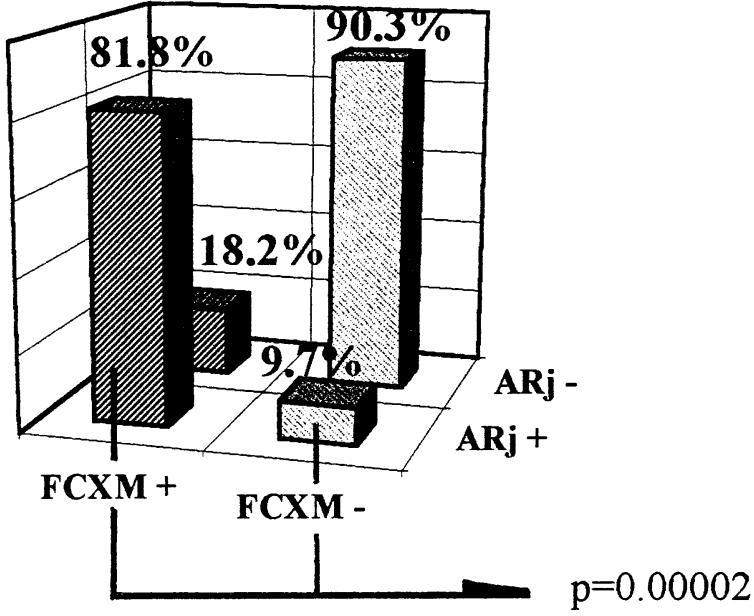

Fig 1. Correlation between ARj incidence and FCXM analysis in the 42 kidney transplant patients.

we found that 9 of the 11 FCXM-positive patients $(81.8 \%)$ experienced at least one ARj episode. Moreover, all four patients who experienced two episodes of $\mathrm{ARj}$ in the period of our observation were in the FCXM-positive group. In contrast, only $3(9.7 \%)$ of the 31 patients with negative FCXM had ARj episodes $(P=.00002)$ (Fig 1). The two FCXM-positive patients who had no acute rejection episode experienced a slight reduction in diuresis and a small increase in serum creatinine levels that did not require further immunosuppressive treatment. The FCXM became negative a few weeks after ARj treatment in those patients who had developed a positive FCXM.

No correlation was found between the degree of FCXM positivity and incidence of ARj. The onset of FCXM positivity was analyzed and correlated to ARj episodes. FCXM monitoring revealed in 11 of the $16(68 \%) \mathrm{ARj}$ episodes the presence of anti-donor-specific antibodies from 7 to 1 days before the clinical appearance of rejection.

\section{DISCUSSION}

It is well accepted that rejection episodes occur in the early posttransplant period and influence long-term graft survival and the incidence of chronic graft rejection. Moreover, some studies have shown that the presence of preformed alloantibodies, detectable only by FCXM, represents a high risk of rejection, ${ }^{2,4,12}$ whereas the relevance of a positive FCXM after transplantation is still unclear.

In accordance with some authors, ${ }^{4,13}$ our data confirm a statistically significantly higher incidence of acute rejection episodes in patients with a positive FCXM when compared to patients with a negative FCXM $(81.8 \%$ versus $9.7 \%, P=$ $.00002)$; all four patients who experienced two rejection episodes in the period of our observation belonged to the group of FCXM-positive patients.

By studying the graft function at 3 months after transplantation we observed that increased serum creatinine 
levels were more common in patients with a positive FCXM than in patients with negative FCXM.

We also analyzed the incidence of HLA-ABDR mismatches in the two groups, however, no differences in the degree of HLA-DR mismatching were found; on the contrary we observed an increase, although not significant, of HLA-AB mean mismatches in the FCXM-positive patients, and it can be assumed that this greater HLA-class I incompatibility might well stimulate the development of posttransplant donor-specific antibodies.

Our study indicates that FCXM combines sensitivity with specificity in evaluating the patients' response to the graft. In accordance with some authors, ${ }^{4}$ we found that the clinical observation of rejection in $68 \%$ of rejection episodes was preceded by several days by the appearance of a positive FCXM. These data support our hypothesis that FCXM can be used as a prediction marker of rejection.

In conclusion, our study suggests that FCXM is a sensitive, noninvasive tool for the assessment of rejection in renal transplant recipients that can be performed whenever the recipient's clinical status indicates the possibility of rejection, and that FCXM is a promising approach for the evaluation of posttransplant donor specific immune response.

\section{REFERENCES}

1. Garavoy MR, Rheinschmidt MA, Bigos M, et al: Transplant Proc 15:1939, 1983

2. Lazda VA, Pollak R, Mozes MF, et al: Transplantation 45:562, 1988

3. Mahoney RJ, Ault KA, Given SR, et al: Transplantation 49:527, 1990

4. Scornik JC, Salomon DR, Lin PB, et al: Transplantation 47:287, 1989

5. Chapman JR, Deierhoi MH, Carter NP, et al: Transplant Proc 17:2480, 1985

6. Cook DJ, Terasaki PI, Iwaki Y, et al: Clin Transplant 1:253, 1987

7. Talbot D, Cavanagh G, Coates E, et al: Transplantation 53:925, 1992

8. Ferguson RM: Transplant Rev 9:121, 1995

9. Berteli AJ, Daniel V, Möhring K, et al: Clin Transplant 6:31, 1992

10. Sutton PM, Harmer AW, Bayne AM, et al: Transpl Int 8:360, 1995

11. Bray RA: Methods in Cell Biology 41:103, 1994

12. Lazda VA: Transplantation 57:964, 1994

13. Utzig MJ, Blümke M, Wolff-Vorbeck G, et al: Transplantation 63:551, 1997 